\title{
Desalination of Agricultural Wastewater by Solar Adsorption System: A Numerical Study
}

\author{
Jehan F. AlRubaiea ${ }^{a}$, Farkad A. Latteiffa, Jasim M. Mahdia ${ }^{*}$, Mohammed A. Atiya ${ }^{b}$, \\ Hasan Sh. Majdi ${ }^{c}$
}

${ }^{a}$ Department of Energy Engineering, University of Baghdad, Baghdad 10071, Iraq

${ }^{b}$ Al-Khawarizmi College of Engineering, University of Baghdad, Baghdad 10071, Iraq

cDepartment of Chemical Engineering and Petroleum Industries, Al-Mustaqbal University College, Babylon 51001, Iraq

\begin{abstract}
There are still areas around the world suffer from severe shortage of freshwater supplies. Desalination technologies are not widely used due to their high energy usage, cost, and environmental damaging effects. In this study, a mathematical model of single-bed adsorption desalination system using silica gel-water as working pair is developed and validated via earlier experiments. A very good match between the model predictions and the experimental results is recorded. The objective is to reveal the factors affecting the productivity of fresh water and cooling effect in the solar adsorption system. The proposed model is setup for solving within the commercially-available software (Engineering Equation Solver). It is implemented to solve the mass and heat balance equations for the adsorbent bed, condenser, and evaporator components. At a typical temperature of $89{ }^{\circ} \mathrm{C}$ and flow rate of $30 \mathrm{~m}^{3} / \mathrm{sec}$ for the hot water entering the bed, the following results are reported: (a) the specific daily water production of $1.89 \mathrm{~m}^{3} / \mathrm{ton}$ of silica gel/ day, (b) coefficient of performance of 0.32 , and (c) specific cooling power of $40.82 \mathrm{~W} / \mathrm{kg}$ of silica gel. The concentration of salt (X) in the product (desalinated water) has been set with value of $0.5 \mathrm{gm} / \mathrm{kg}$ to be suitable for drinking and irrigation. The salt concentration in the evaporator is estimated to be $4.611 \mathrm{gm} / \mathrm{kg}$ during the overall adsorption process. The results from this study should be of wide interest for the field of solar water desalination and air-conditioning.
\end{abstract}

Keywords: Solar desalination, Agricultural wastewater, Adsorption, Single bed, numerical modelling

Article History: Received: 03 ${ }^{\text {rd }}$ June 2021; Revised: $20^{\text {th }}$ July 2021; Accepted: $5^{\text {th }}$ August 2021; Available online: $16^{\text {th }}$ August 2021

How to Cite This Article: AlRubaie, J.F., Latteiff, F.A., Mahdi, J.M., Atiya, M.A. and Majdi, H.S. (2021) Desalination of agricultural wastewater by solar adsorption system: a numerical study. International Journal of Renewable Energy Development, 10(4), 901-910.

https://doi.org/10.14710/ijred.2021.38798

\section{Introduction}

Water and energy are two of the most important elements to human life, which largely influence the growth and development of human societies. Nowadays, the quest for abundant energy and freshwater witnesses a dramatic increase in demand due to the growth in urban population and industrialization. However, the resources of freshwater on Earth remain very limited and they are estimated to be no more than $3 \%$ against to $97 \%$ as seawater resources. Furthermore, there is only a marginal portion of seawater resources available to humans to turn them into freshwater. In recent decades, rising energy demand has resulted in significant increases in fossil fuel usage (Jahannoosh et al., 2021). Estimates indicate that utilizing renewable sources of energy for seawater desalination account for a small percentage of all freshwater generated in the world. Reasons include the high equipment costs and the growing environmental negative impacts due to the harsh fossil-fuel usage which is in favor of lowering carbon emissions (Naderipour et al., 2021). In several areas around the world, availability of great amounts of solar energy being usually associated with scarcity of freshwater especially in the middle east (Alnajdi et al., 2020). Also, in some rural and isolated areas, the grid electricity is not accessible and the access to freshwater resources is virtually absent. Therefore, the move to utilizing of renewable energy sources like solar seems very practical solution to mitigate the reliance on fossil fuels, reduce the consequences of fossil-fuel usage like the harmful $\mathrm{CO}_{2}$ emissions, and save the high costs of supplying freshwater. In this regards, solar-powered desalination appears as a very dependable technology that has the potential to resolve the shortage of sufficient freshwater supplies at rural and isolated parts of the world.

There are various methods to produce freshwater using the desalination technologies. These technologies are divided according to the kind of the energy source driving the process as thermally-driven techniques such as multi-stage flash (MSF), multi-effect distillation and mechanical-and-thermal vapor compression and pressuredriven techniques such as Reverse osmosis (RO). There are some disadvantages associated with applying these traditional desalination technologies like scaling, fouling, corrosion, and the need for pre- and post-treatment

\footnotetext{
*Corresponding author: jasim@siu.edu
} 
chemicals for seawater. To compensate for these disadvantages, the adsorption desalination is adopted as environment-friendly, highly efficient, and sustainable technology for water desalination. It also considered as an attractive and potentially competitive method compared to the other thermal methods due to its ability to generate freshwater and cooling effect simultaneously (Raj \& Baiju, 2019). Furthermore, it could be operated by a lowtemperature heat source like solar energy thus the high operating costs and the risky $\mathrm{CO}_{2}$ emissions associated with the traditional desalination methods could be substantially reduced. Other advantages include the chilled water which is produced as by-product can be employed for cooling or refrigeration purposes. Also, there is ability to work at relatively low temperature and pressure compared to traditional methods which minimizes the undesirable fouling and scaling. More important, the absence of moving parts makes the maintenance cost to be very low compared to the other methods (Woo et al., 2019).

Sakoda \& Suzuki, (1984) presented an experiment on a solar-powered adsorption cooling system which simulated a functional unit by using a mixture of silica-gel and water vapor as adsorbent-adsorbate mixture. The transitional behaviour of heat and mass transfer was interpreted successfully by the model. Chua et al., (2002) studied experimentally the adsorption characteristics of pure water vapor onto two different types of silica gel. The Toth isotherm model is used to match all of the experimental results within the bounds of the experimental errors. The model is found to be able to accurately explain the efficiency of type A and RD silica gels. Ng et al., (2009) investigated the performance of a two-bed adsorption cycle that uses solar hot water to generate cooling and desalination effects. They showed that with SCC range of 25-35 Rton/tonne of silica gel, the $\mathrm{AD}$ cycle generates chilled water at temperatures ranging from 7 to $108^{\circ} \mathrm{C}$ and provides SDWP of $3-5 \mathrm{~m}^{3}$ per tonne of silica gel per day. Thu et al., (2013a) investigated three types of silica gels (Type-A5BW, Type-A++ and Type- RD 2560). They observed that the Type-A++ silica gel (granular type) has the largest surface area of $863.6 \mathrm{~m}^{2}$ per gram, followed by type-A5BW and Type-RD 2560, respectively. They investigated the pore size of the silica gels, and found that their pore diameters range from 10 to 30 microns. (Rezk et al., 2019) proposed a silica gel-based on mathematical model for the SADC method (solar adsorption desalination cycle) based on result from experimental study. They optimized the performance of (SADC) system by employing a modern optimizer to evaluate the optimal cooling, heating, cycle time, and heating water flow rate.

Li et al., (2003) introduced simulation results for a solar refrigerator in which zeolite is put within the solar collector's evacuated tubes. It is found that the overall device efficiency is superior to previous solar adsorption refrigerators, with potential solar COP values exceeding 0.25. Zejli et al., (2004) presented a multi-effect desalination system that uses zeolite as the solid vapor adsorbent and runs on an adsorption heat pump with an open cycle. They showed that the regeneration efficiency decreased with increasing of time. Ullah et al., (2013) presented a review of various solar thermal refrigeration systems, with various working fluids. They reported that zeolite-water pair is better suited for air-conditioning applications. Ali \& Chakraborty, (2016) investigated an adsorption desalination system using two adsorbents (zeolite and silica gel). They discovered that the silica gel is suitable for water production system, zeolite is a viable choice for cooling system. Alsaman et al., (2017) evaluated the adsorption characteristics for two-bed adsorption desalination system using 13.5 percent silica gel. They reported a specific cooling power of $112 \mathrm{~W} / \mathrm{kg}$ and a specific daily water production of $4 \mathrm{~m}^{3}$ per ton silica gel with COP of 0.45. Kowsari et al., (2018) developed A three dimensional numerical scheme to investigate the impact of geometrical structure on the performance of a trapezoidal aluminium finned flat-tube heat exchanger in a single bed adsorption chiller. They found that the heat transfer resistance is primarily influenced by both the fin pitch and height in this form of Hex, while the inter-grain mass transfer resistance is regulated independently by the bed length. The fin height has a greater impact on the COP than the fin pitch, and the bed length has only small effects at a given fin height and pitch. (Raj \& Baiju, 2019) studied adsorption desalination of single-bed system and their theoretical analysis was based on the performance parameters such as fresh water production, coefficient of performance and energy consumption per $\mathrm{kg}$ of water produced. (Amirfakhraei et al., 2020) implemented a new operation cycle for two-bed adsorption desalination cycle with heat and mass recovery between the adsorption beds, the condenser and the evaporator. They found that at a hot water temperature of $95{ }^{\circ} \mathrm{C}$ and cold water of $30{ }^{\circ} \mathrm{C}$, the specific daily water output (SDWP) is $9.58 \mathrm{~m}^{3} /$ ton of silica gel/day. (Naeimi et al., 2020) provided theoretical framework focused on a modern advanced adsorption desalination and cooling system with internal heat recovery and double-cycle multi-bed dual-evaporator. They showed that contrary to the single-cycle multi-bed dual evaporator design, SDWP in the proposed configuration increases by $20 \%$. Zhang et al., (2020) presented a $100 \mathrm{~kg} / \mathrm{h}$ water production pilot-scale adsorption desalination system. The results showed that when the temperature of the hot water entering the desorper is $55^{\circ} \mathrm{C}$ and the flow rate is $28 \mathrm{~m}^{3} / \mathrm{h}$, the rate of water production exceeds $100 \mathrm{~kg} / \mathrm{h}$. Bai et al., (2020) developed a mathematical model taking into account the influence of salinity on the physical properties of saltwater. They found that the specific cooling power and specific daily water production are $490 \mathrm{~W} / \mathrm{kg}$ and 18 $\mathrm{m}^{3} /$ tone adsorbent/day for seawater under the operating conditions of desorption temperature at $85{ }^{\circ} \mathrm{C}$ and evaporation temperature at $14^{\circ} \mathrm{C}$. Ali et al., (2021) proposed a new combination of ADS with liquid-vapor ejector to boost freshwater productivity. It is found the proposed system using a desorption temperature of $95{ }^{\circ} \mathrm{C}$ can produce specific daily freshwater higher by a factor of 5.0 .

In this paper, the mathematical modelling of solar adsorption desalination system with a new design under Iraq climate conditions is conducted and experimentally validated. An effective design with lower cost has been developed in this system since the high cost of installing solar modules is seen as an obstacle to their widespread usage. Domestic evacuated-tube solar collectors which are mainly mounted over homes and buildings roofs have been used in this research. The use of this type of solar collector helps in reducing the installing cost of the solar adsorption desalination system. It is designed to test the system 
performance in terms of specific daily water production (SDWP), cooling performance assessment indicators such as the specific cooling power (SCP) and coefficient of performance (COP) at different working-fluid temperatures. In addition, the effects of various operating parameters on desalination and cooling performance, such as saltwater salinity, hot water, cold water, chilled water inlet temperature, are all investigated in this modelling study.

\section{System description}

The adsorption cooling system (AC) of (Lattieff et al., 2019) has been modified to match the new proposed configuration with water desalination strategies as shown in Fig. (1). In this configuration, the system modification includes separating the connecting line between the condenser and the evaporator in order to collect the distilled water in a tank. Also, the amount of salt water is added to the evaporator during the operation through a line for entering and exiting the saltwater stream from the evaporator. Thus the system can be described as a continuous desalination system with this new configuration. Fig. (1) Shows the single bed ADS's schematic plan. Desalination occurs during the desorption process, while the cooling effect occurs during the cycle's adsorption process. After degassing the entire system and charging the evaporator with salt water, the evaporation is accomplished by the adsorbent substance up taking water vapor. The unsaturated silica gel type (A) which packed into a tube heat exchanger located within a reactor bed adsorbs water vapor. Table 1 shows the properties of the silica gel used in this work. A continuous vapor adsorption is achieved when the valve between the adsorption bed and the evaporator is opened. The heat of adsorption is released during the adsorption process. The saturated silica gel can be regenerated by introducing hot water at a low temperature from a heat source, which is known as the desorption process. The connecting vapor valves are set to open position after the switching time, and the regenerated water vapor flows to the condenser to provide distilled water. The heat of condensation is rejected into cooling water flowing through the condenser, and the condensate is stored as desalinated water. The heating water valve is opened to begin the preheating phase, and the adsorbent pressure and temperature are increased. The condenser-bed valve opens when the pressure inside the bed reaches that of the condenser. During the precooling process, cooling water valve is opened to lower the temperature of the adsorbent, which rises due to the physical contact between the vapor and the adsorbent. Then valve between the evaporator and bed is opened during adsorption process. After cycle time, the previous phases are rebated with desorption and adsorption processes.

Table 2 shows the timetable used in this research for the single-bed adsorption desalination system in use. The time for preheating and precooling processes is given by switching time. It can be observed from the table that the switching time for preheating process is 20 minutes and for precooling process is 10 minutes, while the time for desorption and adsorption process are 20 and 10 minutes, respectively. So, the complete cycle time for all process is being 60 minutes.

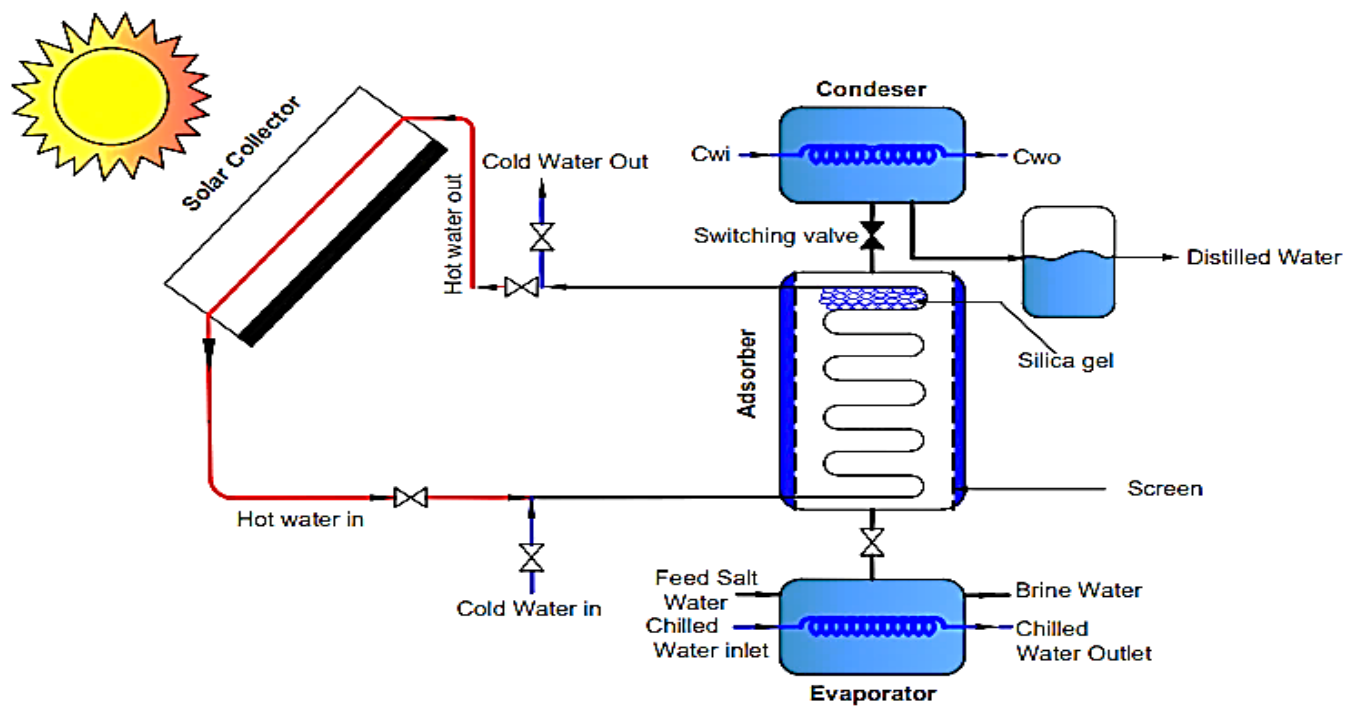

Fig.1 Schematic of the single-bed adsorption desalination system.

Table 1

Properties of silica gel type A.

\begin{tabular}{ll}
\hline Property & Value \\
\hline Apparent density & $750 \mathrm{~kg} / \mathrm{m} 3$ \\
Average particle diameter & $6 \mathrm{~mm}$ \\
Surface area & $650-700 \mathrm{~m}^{2} / \mathrm{g}$ \\
Thermal conductivity & $0.198 \mathrm{~W} / \mathrm{m} . \mathrm{K}$ \\
Specific heat capacity & $921 \mathrm{~J} / \mathrm{kg} . \mathrm{K}$ \\
\hline
\end{tabular}


Table 2

Schematic of the single bed timing scheme

\begin{tabular}{llll}
\hline Preheating & Desorption & Precooling & Adsorption \\
\hline$(10 \mathrm{~min})$ & $(20 \mathrm{~min})$ & $(20 \mathrm{~min})$ & $(10 \mathrm{~min})$
\end{tabular}

\section{Mathematical modeling}

A single bed adsorption desalination system is simulated to assess its ability to produce fresh water. Energy equations for the evaporator, condenser, and adsorption bed, as well as mass and salt balance equations for the evaporator, are solved in order to analyze the cycle. The mathematical model presented here is implemented to numerically simulate the real working conditions of the solar adsorption desalination system. The following assumptions are made to make the mathematical analysis easier to understand:

1. Pressure, temperature and the amount of adsorbate in the adsorption bed are uniform.

2. Adsorbate vapor, metal tube, and fluid properties are all constant.

3. The evaporator is well insulated.

4. The flow resistance caused by pipeline water flow is neglected.

\subsection{Isotherms of adsorption and adsorbate uptake}

The adsorption/desorption rate is a main parameter for determining the silica gel's performance. This is one of the most important parameters to consider, since it is related to the adsorbent's temperature, which is increased by the solar collector. The transient uptake is expressed as follows using the linear driving force (LDF) model, (Alsaman et al., 2017)

$\frac{d x}{d t}=k_{m} *(\mathrm{xeq}-x)$

where:

$k_{m}=\left(\frac{15 * D o}{R_{p}^{2}}\right) \exp \left(\frac{-E_{a}}{R T_{\text {bed }}}\right)$

$\mathrm{K}_{\mathrm{m}}$ known as overall mass transfer coefficient, Do is the adsorbent's diffusion factor in the adsorbent that equals $2.54 \cdot 10^{-4} \mathrm{~m}^{2} / \mathrm{s}, \mathrm{E}_{\mathrm{a}}$ is the surface diffusion activation energy, which is $4.20 \cdot 10^{4} \mathrm{~J} / \mathrm{mole}$, the universal gas constant $R$ is given as $8.314 \mathrm{~J} /$ mole.K, $R_{p}$ is the radius of particle.

Adsorption isotherms must be determined in order to measure the amount of vapor adsorbed by the silica gel at various pressure ratios. Dubinin-Astakhov equation as stated in (Wang et al., 2005) was used for calculation of adsorption equilibrium uptake by the silica gel:

$$
x e q=x_{0} * \exp \left[-K *\left(R T_{\text {bed }} * \ln \left(\frac{P_{\text {bed }}}{P_{\text {evap }} / \text { cond }}\right)\right)^{n}\right]
$$

Here $\mathrm{x}_{\text {eq }}$ is the amount adsorbed in equilibrium with $\mathrm{Pb}_{\mathrm{b}}$ is the pressure of bed, $\mathrm{Pe} / \mathrm{c}$ is the saturation vapor pressure, $\mathrm{n}=1.6$

The Antoine equation is used to measure the saturation pressure which can be expressed in the following way:

$$
\begin{aligned}
& P_{b}=133.31 *\left(\exp \left(18.1-\frac{3820}{T_{b}+273-46.1}\right)\right) \\
& x=x e q \cdot\left(1-e^{-k_{m} \cdot t}\right) \\
& \Delta x=\left(x^{*}\left(T_{i}\right)-x^{*}\left(T_{i-1}\right) *\left(1-\exp \left(-k_{m} * t\right)\right.\right.
\end{aligned}
$$

\subsection{Equations of energy balance}

\subsubsection{Energy balance of the adsorption bed}

The single bed adsorption desalination operates in two modes: adsorption and desorption when it is attached to the evaporator and condenser, respectively. In the adsorption/desorption mode, the energy balance can be written as follows:

$$
\begin{aligned}
& \left(M_{s g} C p_{s}+M_{s g} C p_{w r} x+M_{m l} C p_{m l}\right) \frac{d T_{b}}{d t}= \\
& m_{h w} C p_{h w}\left(T_{h w i}-T_{h w o}\right)+\left(H_{a}-C p_{w r} T_{b}\right) M_{s g} \frac{d x_{d e s}}{d t} \\
& \left(M_{s g} C p_{s}+M_{s g} C p_{w r} x+M_{m l} C p_{m l}\right) \frac{d T_{b}}{d t}= \\
& m_{c w} C p_{c w}\left(T_{c w i}-T_{c w o}\right)+\left(H_{a}-C p_{w r} T_{b}\right) M_{s g} \frac{d x_{a d s}}{d t}
\end{aligned}
$$

Here $H_{a}$ represent the heat of adsorption.

\subsubsection{Energy balance for condenser}

In the condenser, the desorbed water vapor has been condensed and delivered to the collecting tank. The condenser's energy balance can be expressed as follows:

$$
\begin{aligned}
& \left(M_{\mathrm{w}, \text { cond }} c p\left(T_{\text {cond }}\right)+M_{\mathrm{ml}} c p_{\mathrm{ml}}\right) \frac{d T_{\text {cond }}}{d t} \\
& =\frac{d M_{d}}{d t} h_{f}\left(T_{\text {cond }}\right)+M_{\mathrm{sg}} \frac{d x_{d e s}}{d t} h_{f g}\left(T_{\text {cond }}\right)+\dot{m}_{\mathrm{cw}, \text { cond }} c p_{w}\left(T_{\text {cond }}\right) \\
& \left(T_{c w, \text { in }}-T_{\text {cw,out }}\right)_{\text {cond }}
\end{aligned}
$$

Where $M_{\mathrm{w} \text {, cond }} C p$ and $M_{\mathrm{ml}} C p$ refer to condensate water capacity and condenser heat capacity, respectively. $M_{d}$ Is the mass of the desalinated water.

\subsubsection{Energy balance for evaporator}

$$
\begin{aligned}
& {\left[M_{\text {s,evap }} c_{p_{s}}\left(T_{\text {evap }}\right)+M_{m l} c_{p_{\mathrm{ml}}}\right] \frac{d T_{\text {evap }}}{d t}} \\
& =h_{f}\left(T_{\text {evap }}\right) m_{\mathrm{s}, \text { in }}-h_{f g}\left(T_{\text {evap }}\right) \frac{d x_{\text {des }}}{d t} M_{\mathrm{sg}}+m_{c h} c_{p_{\mathrm{ch}}}\left(T_{c h, \text { in }-}\right. \\
& \left.-T_{\text {ch,out }}\right)-h_{f}\left(T_{\text {evap }}\right) m_{b}
\end{aligned}
$$

Where $M_{s}$ and $M_{m l}$ are seawater and evaporator metal heat capacities, respectively. The right-hand side of the equation has four terms: inlet heat of feed salt water, latent heat of evaporation, sensible heat transfer of chilled water and heat of discharge concentrated brine.

\subsection{Mass balance equation}

In an evaporator, the mass balance of seawater is written as:

$\frac{d M_{\mathrm{s}, \mathrm{evap}}}{d t}=m_{\mathrm{s}, \text { in }}-m_{p}-m_{b}$

Where $\mathrm{M}_{\mathrm{s} \text { evap }}$ is the amount of seawater in evaporator, $m_{s, i n}$ is the rate at which seawater enters the evaporator, 
$m_{p}$ the amount of pure water, $m_{b}$ is the mass of concentrated brine discharged, Msg the mass of silica gel

$\frac{d M_{\mathrm{s}, \mathrm{evap}}}{d t}=m_{\mathrm{s}, \mathrm{in}}-\frac{d X a}{d t} * M s g-m_{b}$

$M_{\mathrm{s}, \text { evap }} \frac{d X_{\mathrm{s}, \text { evap }}}{d t}=X_{\mathrm{s}, \text { in }} m_{\mathrm{sw}, \text { in }}-X_{\mathrm{s}, \text { in }} m_{\mathrm{b}}-X p * d X a / d t * M s g$

Here $X_{s, i n}$ is the concentration of the salt water inter the evaporator, $X_{p}$ is the concentration of the product (desalinated water).

The temperature of the bed, condenser, and evaporator heat exchanger's outlet water was determined by using the formula for the log mean temperature difference (LMTD) is as follows:

$$
\begin{aligned}
& T_{h w o}=T_{\text {bed }}+\left(T_{h w i}-T_{\text {bed }}\right) \exp \left(-\frac{U_{b e d} A_{b e d}}{m_{h w} C p_{h w}}\right) \\
& T_{c w o}=T_{\text {bed }}+\left(T_{c w i}-T_{\text {bed }}\right) \exp \left(-\frac{U_{b e d} A_{b e d}}{m_{c w} C p_{c w}}\right) \\
& T_{c w o}=T_{\text {cond }}+\left(T_{c w i}-T_{\text {cond }}\right) \exp \left(-\frac{U_{c o n d} A_{c o n d}}{m_{c w} C p_{c w}}\right) \\
& T_{\text {cho }}=T_{\text {evap }}+\left(T_{\text {chi }}-T_{\text {evap }}\right) \exp \left(-\frac{U_{\text {evap }} A_{\text {evap }}}{m_{c h w} C p_{c h w}}\right)
\end{aligned}
$$

Finally, the efficiency of the system is measured using the Qc (heat of evaporation), SCP (specific cooling power), coefficient of performance (COP) and SDWP (specific daily water production).

$$
\begin{aligned}
& Q c=\frac{\left(M s g \Delta x \Delta H_{a d s}\right)}{t} \\
& S C P=\frac{Q c}{M s g} \\
& C O P=\frac{Q c}{\left(m_{h} c_{p}\left(T_{h w, i}-T_{h w, o}\right)\right.} \\
& S D W P=\frac{N_{\frac{c y c l e}{d a y}} \int_{0}^{t_{c y c l e}}\left(\frac{d x_{a d s}}{d t}\right) d t}{M_{t o t}}
\end{aligned}
$$

The equations of the mathematical modeling of adsorption desalination system are solved using EES (Engineering Equation Solver) is a modern computer tools. The parameters used in the simulation program are listed in Table 3.

\subsection{Model validation}

In this study, the present adsorption cooling system without water desalination model is validated using (Lattieff et al., 2019)'s experimental work. The performance parameters including SCP, COP are adopted in the validation. The following step is to suggest a new adsorption cooling system with water desalination capabilities. The effects of different parameters on the efficiency of the new adsorption-cooling (ADC) system are

\begin{tabular}{|c|c|}
\hline Parameter & Value \\
\hline $\mathrm{m}_{\mathrm{hw}}$ & $0.5(\mathrm{~kg} / \mathrm{s})$ \\
\hline $\mathrm{m}_{\text {cwi }}$ & $0.2(\mathrm{~kg} / \mathrm{s})$ \\
\hline $\mathrm{m}_{\text {salt water }}$ & $0.0004(\mathrm{~kg} / \mathrm{s})$ \\
\hline $\mathrm{X}_{\mathrm{p}}$ & $0.5 \mathrm{gm} / \mathrm{kg}$ \\
\hline $\mathrm{T}_{\text {hwi }}$ & $89^{\circ} \mathrm{C}$ \\
\hline $\mathrm{T}_{\mathrm{cwi}}$ & $26^{\circ} \mathrm{C}$ \\
\hline $\mathrm{T}_{\text {chi }}$ & $14.5^{\circ} \mathrm{C}$ \\
\hline Msg & $10 \mathrm{~kg}$ \\
\hline Mshell & $80 \mathrm{~kg}$ \\
\hline Mcoil, Mscreen & $2 \mathrm{~kg}$ \\
\hline Cp screen (aluminium) & $900 \mathrm{~J} / \mathrm{kg} . \mathrm{K}$ \\
\hline Cp coil (copper) & 385 J/kg.K \\
\hline $\mathrm{Cp}_{\text {shell }}$ & 479 J/kg.K \\
\hline $\mathrm{Cp}_{\mathrm{hw}}$ & 4188 J/kg.K \\
\hline $\mathrm{Cp}_{\mathrm{cw}}$ & 4179 J/kg.K \\
\hline $\mathrm{Cp}_{\text {chilled }}$ & 4188J/kg.K \\
\hline Abed & $0.351 \mathrm{~m}^{2}$ \\
\hline A evap & $0.5 \mathrm{~m}^{2}$ \\
\hline Acond & $0.1 \mathrm{~m}$ \\
\hline
\end{tabular}
then investigated. Fig 2 shows a comparison between the present model with water desalination and the experimental temperature profile for adsorption bed. It shows that the present model can predict the experimental findings with good degree of precision.

Table 3

Values of the operating parameters used in the simulation model. 


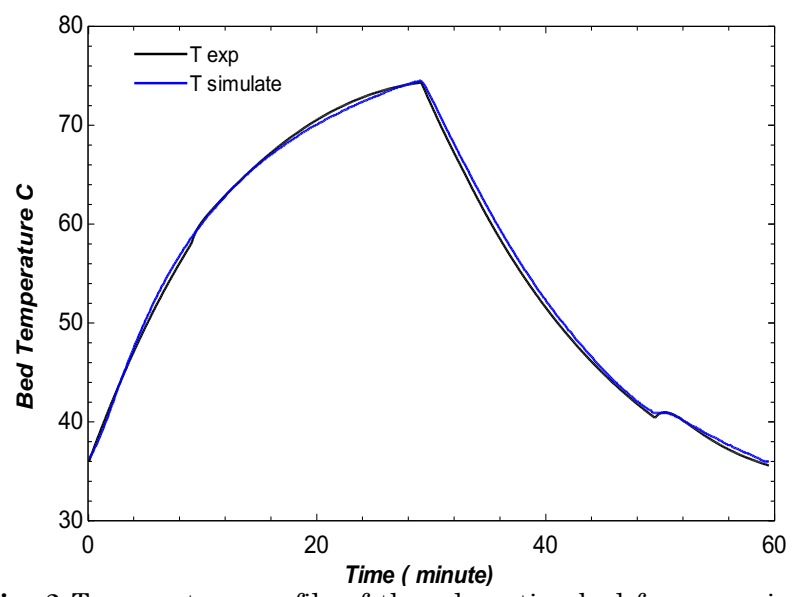

Fig. 2 Temperature profile of the adsorption bed for numerical model and experimental data during adsorption/desorption cycles.

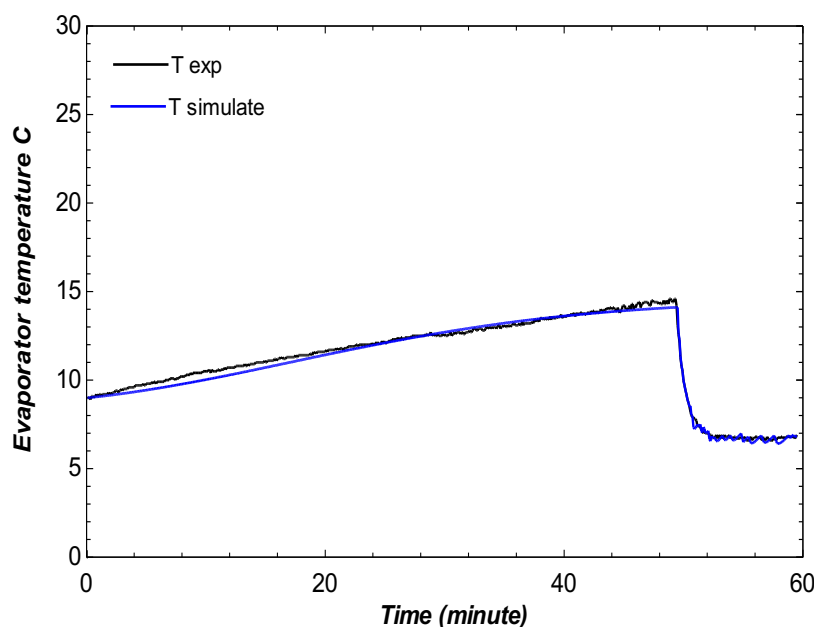

Fig. 3 Evaporator temperature predicted by the present model against those by (Lattieff et al., 2019).

In order to be more confident, Fig. (3) Which displays the evaporator temperature profile is adopted to make another comparison of the present model prediction with the experimental data of (Lattieff et al., 2019). It also shows a good agreement between the two studies. Hence, the present model is considered a reliable enough to be adopted to study the proposed $\mathrm{ADC}$ system.

\section{Results and Discussion}

After model validation, a new adsorption cooling system has been proposed with water desalination capability. Fig.4 illustrates the measured adsorption bed temperature at different inlet hot water temperatures at $70,80,90^{\circ} \mathrm{C}$. As indicated, the peak bed temperature $\mathrm{T}_{\mathrm{b}}$ $=74.6{ }^{\circ} \mathrm{C}$ is achieved when the hot water inlet temperature is $90{ }^{\circ} \mathrm{C}$. During the desorption period, a higher bed temperature would cause a large amount of adsorbed vapor to be released. As a result, higher adsorption capacity is obtained. This is very important because it lowers the evaporator temperature, which contributes to increasing of cooling power.

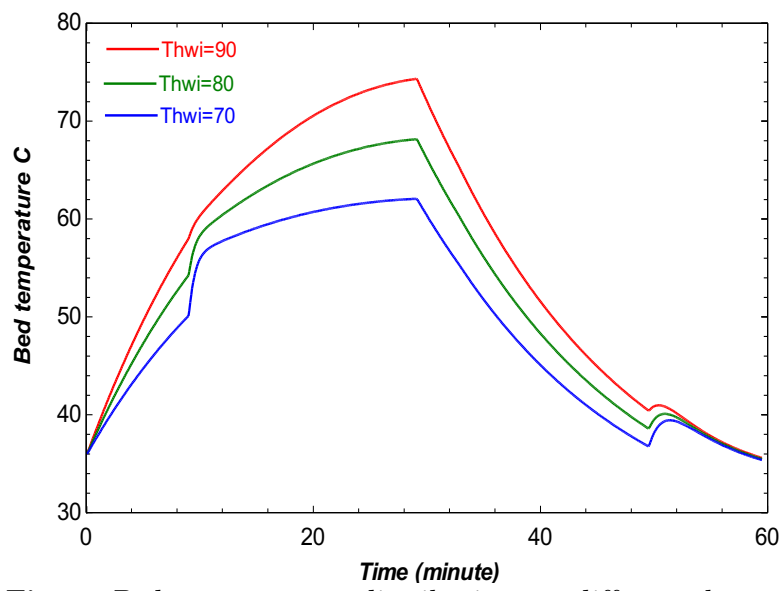

Fig 4. Bed temperature distribution at different hot water temperature.

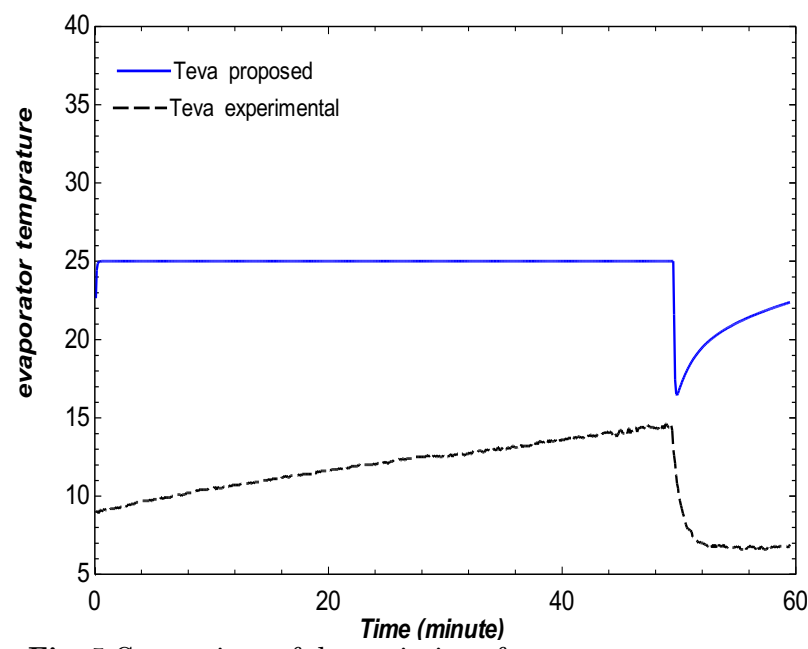

Fig. 5 Comparison of the variation of evaporator temperature for the experimental and proposed model.

Fig (5) demonstrate the evaporator temperature profiles for the adsorption system with and without water desalination. It is observed that the temperature of evaporator for the proposed system with water desalination is steady at $25^{\circ} \mathrm{C}$ before adsorption time phase is started. When the valve between evaporator and adsorber is first opened at the beginning of the adsorption time the evaporator temperature decreases to $21.6^{\circ} \mathrm{C}$. When the adsorption time exceeds one minute, the evaporator temperature drops to $17.9^{\circ} \mathrm{C}$, then rises to 22.4 ${ }^{\circ} \mathrm{C}$ at the end of the adsorption time. The cause for this rise is the flow of salt water within the evaporator. Comparably, in an adsorption cooling system without desalination, the evaporator temperature rises gradually between $8.9^{\circ} \mathrm{C}$ and $14^{\circ} \mathrm{C}$ before the adsorption phase begins. The insufficient isolation of the evaporator during this period causes heat transfer through the system's valves resulting in a progressive rise in temperature. Also, the temperature reaches $6.7^{\circ} \mathrm{C}$ at the start of the adsorption time and remains fairly constant until the end of adsorption phase. 


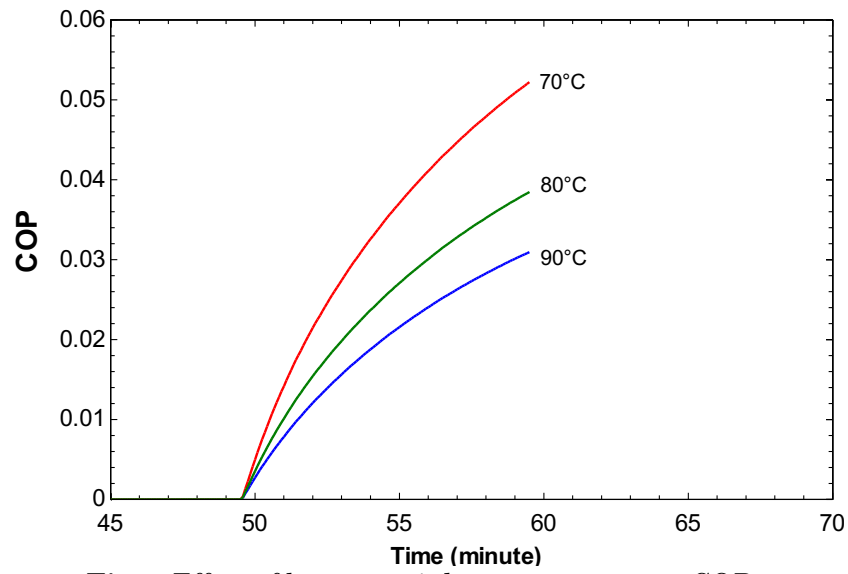

Fig. 6 Effect of hot water inlet temperature on COP.

Effect of hot water inlet temperature on COP is shown in Fig. 6 which illustrates that COP has the optimum value at $\mathrm{T}=70^{\circ} \mathrm{C}$. As shown in Fig. 6 at $\mathrm{T}=80^{\circ} \mathrm{C}$ and $90^{\circ} \mathrm{C} \mathrm{COP}$ begins to decrease above this temperature. It can be deduced that when the regeneration temperature rises, the COP increases until it reaches $70{ }^{\circ} \mathrm{C}$. The explanation for this is up to $70^{\circ} \mathrm{C}$, all of the adsorbate is desorbed, and afterwards the amount of desorbed adsorbate rapidly decreases. Furthermore, as compared to Qc (heat of evaporation), COP drops due to the high increase in heat input. This is related to the design of the adsorption bed heat exchanger, which results in insufficient heat transfer, lowering adsorption capacity and Qc, as well as lowering the COP.

Fig. 7 shows specific cooling power (SCP) with cycle time at different hot water inlet temperatures. This figure indicates an improvement in SCP with an increase in hot water inlet temperature, and the peak value of SCP = 40.82 is obtained at $\mathrm{T}_{\mathrm{hwi}}=90{ }^{\circ} \mathrm{C}$. Typically, SCP is zero before the adsorption process started. However, the cooling effect substantially rises when the valve between the evaporator and the adsorber is opened at the start of the adsorption time. Because the initial adsorption rate and the equilibrium adsorption rate are so dissimilar, SCP reaches its peak value of dry adsorbent. This implies that a 10-minute adsorption period is adequate to complete the hydration of silica gel.

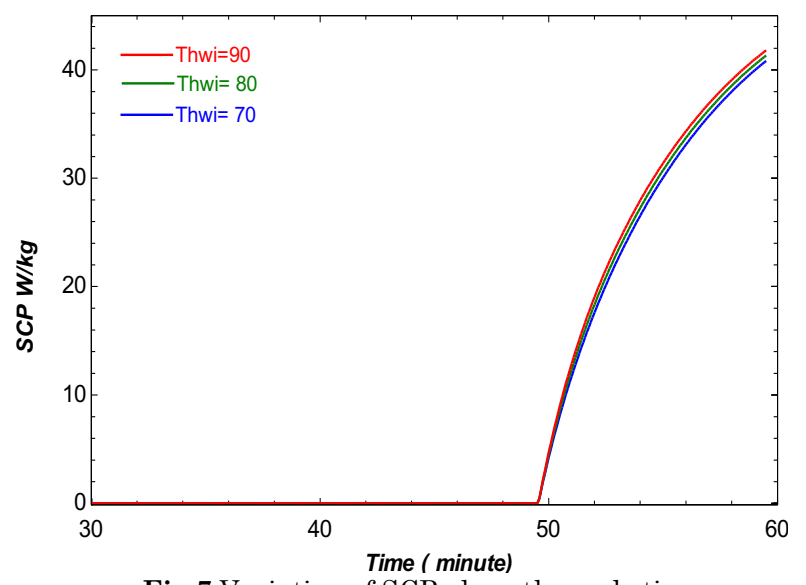

Fig.7 Variation of SCP along the cycle time.

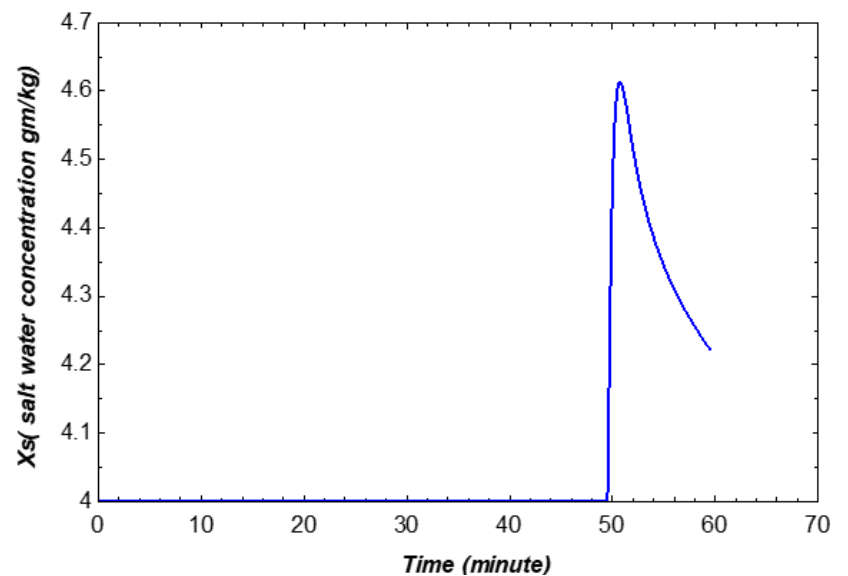

Fig. 8 Variation of concentration of feed salt water with cycle time.

The concentration of the feed salt water in the shell side of the evaporator is shown in Fig.8. Accordingly, when the valve between the evaporator and the bed was opened at the start of the adsorption phase, the salt water concentration (Xs) was $4 \mathrm{gm} / \mathrm{kg}$ and quickly grew to 4.61 $\mathrm{gm} / \mathrm{kg}$ which is caused by the fact that during the adsorption process, the vapor is drawn from the evaporator into the adsorber which leading increasing in the salt concentration. Moreover, it is noticeable that a decrease in salt water concentration occurs after it reaches its maximum value of $4.61 \mathrm{gm} / \mathrm{kg}$. The reason of that is the salt water enter and exits from evaporator which is in continuous flow rate causing in decreasing of salt concentration

Fig.9 illustrates effect of hot water inlet temperature (HWIT) with time on the SDWP (specific daily water production). SDWP is presented for (HWI) temperatures ranging from 70 to $90{ }^{\circ} \mathrm{C}$. The figure indicates that at $\mathrm{T}=90$ ${ }^{\circ} \mathrm{C}$, SDWP has the optimum value of $1.896 \mathrm{~m}^{3} /$ ton silica gel/day. This attributed to the fact that when a higher regeneration temperature is used the amount of vapor regenerated in the adsorption bed increases resulting in an increase in the SDWP. In addition as HWIT rises, the rate of adsorption desalination system increases. This is because the regeneration process gets improved when higher hot water temperatures are used.

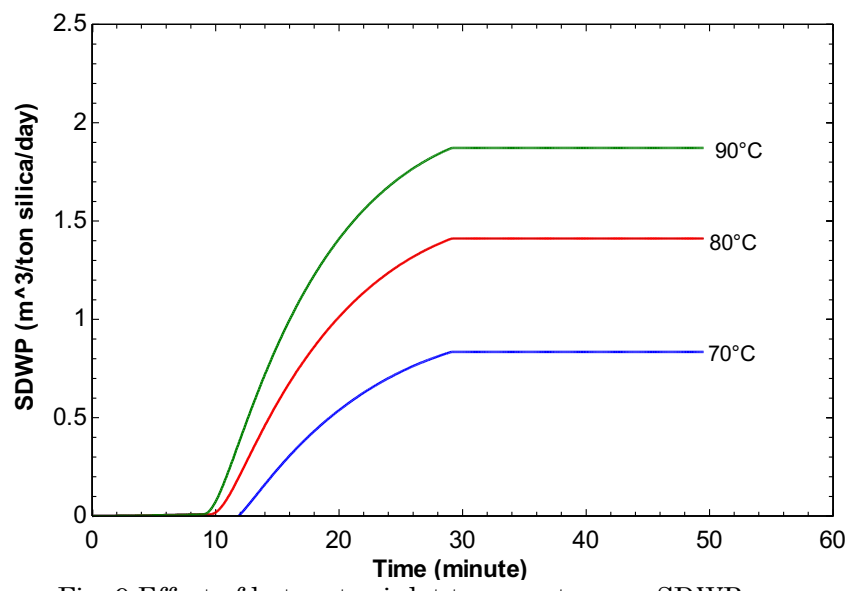

Fig. 9 Effect of hot water inlet temperature on SDWP. 
Citation: AlRubaiee, J.F., Latteiff, F.A., Mahdi, J.M., Atiya, M.A., and Majdi, H.S. (2021) Desalination of agricultural wastewater by solar adsorption system: a numerical study. Int. Journal of Renewable Energy Development, 10(4), 901-910, doi: 10.14710/ijred.2021.38798

908 |

Table 4

Results of this work compared with those of (Alsaman et al., 2017) and (Thu et al., 2013b)

\begin{tabular}{cccccc} 
& No. of beds & $\begin{array}{c}\text { Hot water inlet } \\
\text { temperature }{ }^{\circ} \mathrm{C}\end{array}$ & $\begin{array}{c}\text { Adsorbent } \\
\text { type }\end{array}$ & SDWP $\mathrm{m}^{3 /}$ ton \\
\hline This work & 1 & 89 & Silica gel type & 1.89 & 40.82 \\
Alsaman, 2017 & 2 & 95 & Silica-gel & 4 & 112 \\
Thu, 2013 & 2 & 85 & A++ Silica-gel & 26 & 0 \\
\hline
\end{tabular}

Table 4 compares the results of this work with those of earlier studies on ADS systems. It can be seen that, when an integrated evaporator-condenser design and silica-gel A++ type are used, the maximum SDWP is $26 \mathrm{~m}^{3}$ /ton silica gel/day (Thu et al., 2013b). The evaporator temperature of this system is around $42{ }^{\circ} \mathrm{C}$, which is not appropriate for cooling thus SCP $\sim 0$. To make both the cooling effect and freshwater production possible, (Alsaman et al., 2017) decreases SDWP to $4 \mathrm{~m}^{3} /$ tone silica $\mathrm{gel} /$ day so that the obtained SCP with value $126 \mathrm{~W} / \mathrm{kg}$. In this work, the obtained values of SDWP and SCP are 1.89 $\mathrm{m}^{3} /$ ton silica gel/ day and $40.82 \mathrm{~W} / \mathrm{kg}$, respectively. This difference is due to the type of adsorber's heat exchanger that used by Alsaman et al., (2017). They used finned tube heat exchanger, which improves the heat transfer rate thus leads to higher adsorption power and greater cooling capacity as well.

\section{Conclusions}

In this research, the mass and heat balance equations are used to model a single-bed adsorption desalination system powered by solar energy. The system uses the silica gel-water pair as working fluid. A computational code has been developed and implemented for solving the proposed mathematical model. The results revealed that the model has good potential to precisely predict the continuous water desalination via the proposed system design at different operating conditions. The effects of Various operational parameters on the performance of solar adsorption desalination are revealed. These parameters include the inlet hot water temperature, cooling water temperature, inlet chilled water temperature, adsorption/desorption phase time and saltwater salinity. The concentration of saltwater $(\mathrm{X})$ is estimated to be $4.61 \mathrm{gm} / \mathrm{kg}$ in the evaporator as a result of adsorption process over a cycle period of 60 minutes. Meanwhile, the specific daily water production of seawater (SDWP), specific cooling power (SCP) and coefficient of performance (COP) are estimated as $1.89 \mathrm{~m}^{3 /}$ ton silica gel/ day, $40.82 \mathrm{~W} / \mathrm{kg}$ and 0.32 respectively. Based on the results obtained, the following conclusions can be drawn: (1) saltwater with higher salinities can result in decreased cooling and desalination performance under the same conditions, (2) increasing the hot water temperature while decreasing the cooling-water temperature can boost better adsorbent's equilibrium adsorption capacity and leads to higher freshwater production and cooling impact, and (3) the optimal time for desorption/ adsorption phase is dependent on the equilibrium adsorption rate that the silica gel is reached.

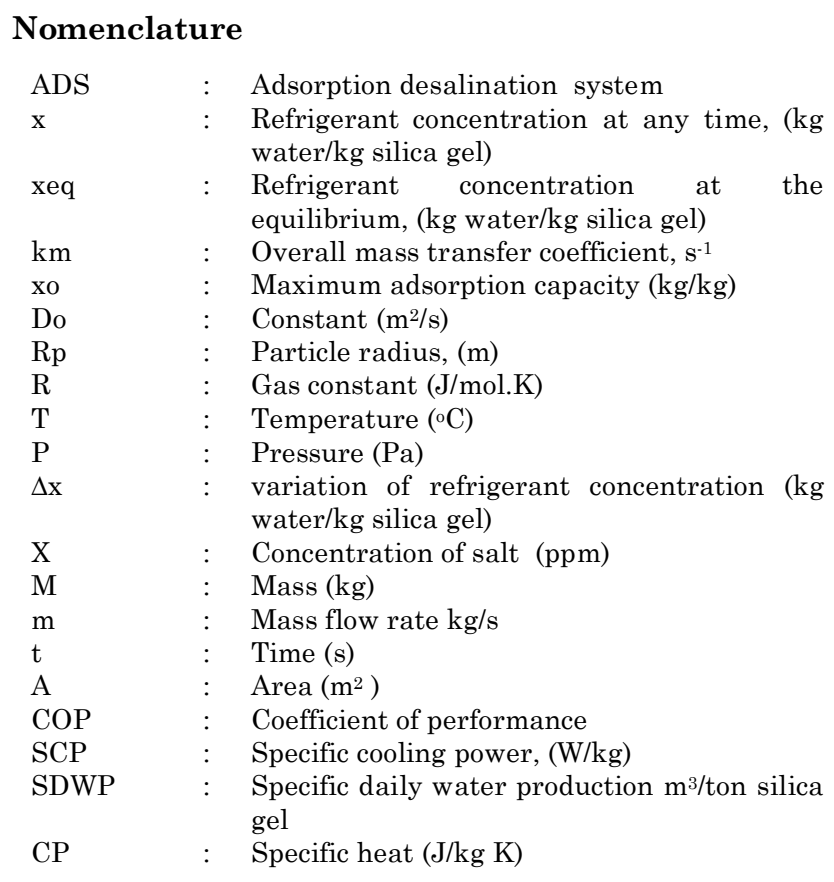

\section{Subscripts / Superscript}

$\begin{array}{lll}\text { sg } & : & \text { Silica gel } \\ \text { hwi } & : & \text { Hot water inlet } \\ \text { hwo } & : & \text { Hot water outlet } \\ \text { wr } & : & \text { Water refrigerant } \\ \text { des } & : & \text { Desorption } \\ \text { ml } & : & \text { Metal } \\ \text { cwi } & : & \text { Cold water inlet } \\ \text { cwo } & : & \text { Cold water outlet } \\ \text { d } & : & \text { Desalined water } \\ \text { ch } & : & \text { Chilled water } \\ \text { s } & : & \text { Salt } \\ \text { w } & : & \text { Water } \\ \text { p } & : & \text { Product } \\ \text { cond } & : & \text { Condenser } \\ \text { evap } & : & \text { Evaporator } \\ \text { bed } & : & \text { Adsorption bed } \\ \text { ads } & : & \text { Adsorption }\end{array}$

\section{References}

Ali, E. S., Mohammed, R. H., \& Askalany, A. (2021). A daily freshwater production of $50 \mathrm{~m} 3 /$ ton of silica gel using an adsorption-ejector combination powered by low-grade heat. Journal of Cleaner Production, 282, 124494. https://doi.org/10.1016/j.jclepro.2020.124494

Ali, S. M., \& Chakraborty, A. (2016). Adsorption assisted double stage cooling and desalination employing silica gel + water and AQSOA-Z02 + water systems. Energy Conversion And 
Management,

117

https://doi.org/10.1016/j.enconman.2016.03.007

Alnajdi, O., Wu, Y., \& Calautit, J. K. (2020). Toward a sustainable decentralizedwater supply: Review of adsorption desorption desalination (ADD) and current technologies: Saudi Arabia (SA) as a case study. Water (Switzerland), 12(4), 1-30. https://doi.org/10.3390/W12041111

Alsaman, A. S., Askalany, A. A., Harby, K., \& Ahmed, M. S. (2017). Performance evaluation of a solar-driven adsorption desalination- cooling system. 128, 196-207.

Amirfakhraei, A., Zarei, T., \& Khorshidi, J. (2020). Performance improvement of adsorption desalination system by applying mass and heat recovery processes. Thermal Science and Engineering Progress, 18, 100516. https://doi.org/10.1016/j.tsep.2020.100516

Aziz, A. A. A., Hatab, S. I., Moawed, M., Zohir, A. E., \& Berbish, N. M. (2017). Experimental study on the Effect of adsorber with three shapes of conductive material on Performance of Adsorption Refrigeration Tube using Activated Carbon/ethanol pair. In Applied Thermal Engineering. Elsevier https://doi.org/10.1016/j.applthermaleng.2017.12.058

Bai, S., Ho, T. C., Ha, J., An, A. K., \& Tso, C. Y. (2020). Study of the salinity effects on the cooling and desalination performance of an adsorption cooling cum desalination system with a novel composite adsorbent. 181. https://doi.org/10.1016/j.applthermaleng.2020.115879

Chua, H. T., Ng, K. C., Chakraborty, A., Oo, N. M., \& Othman, M. A. (2002). Adsorption Characteristics of Silica Gel + Water Systems. 1177-1181. https://doi.org/10.1021/je0255067

Dechang, W., Jingyi, W., Honggang, S., \& Ruzhu, W. (2005). Experimental study on the dynamic characteristics of adsorption heat pumps driven by intermittent heat source at heating mode. Applied Thermal Engineering, 25(5-6), 927-940.

https://doi.org/10.1016/j.applthermaleng.2004.07.013

Goshayeshi, H. R., Gewad, M., \& Nazari, H. (2015). Investigation on Evaluation of a Solar Intermittent Refrigeration System for Ice Production with Ammonia/Calcium Chloride and Activated. Energy and Power Engineering, 07(10), 433439. https://doi.org/10.4236/epe.2015.710042

Hassan, H. Z., Mohamad, A. A., \& Bennacer, R. (2011). Simulation of an adsorption solar cooling system. Energy, $36(1)$, https://doi.org/10.1016/j.energy.2010.10.011

Iloeje, O. C., Ndili, A. N., \& Enibe, S. O. (1995). Computer simulation of a $\mathrm{CaCl} 2$ solid-adsorption solar refrigerator. Energy, 20(11), 1141-1151. https://doi.org/10.1016/03605442(95)00050-Q

Jahannoosh, M., Nowdeh, S. A., Naderipour, A., Kamyab, H., Davoudkhani, I. F., \& Klemeš, J. J. (2021). New hybrid meta-heuristic algorithm for reliable and cost-effective designing of photovoltaic/wind/fuel cell energy system considering load interruption probability. Journal of Cleaner Production https://doi.org/10.1016/j.jclepro.2020.123406

Lattieff, F. A., Atiya, M. A., \& Al-Hemiri, A. A. (2019). Test of solar adsorption air-conditioning powered by evacuated tube collectors under the climatic conditions of Iraq. Renewable Energy, 142, 20-29. https://doi.org/10.1016/j.renene.2019.03.014

Li, C. H., Wang, R. Z., \& Dai, Y. J. (2003). Simulation and economic analysis of a solar-powered adsorption refrigerator using an evacuated tube for thermal insulation. Renewable Energy, 28(2), 249-269. https://doi.org/10.1016/S0960-1481(02)00045-9

Luiz, F., \& Netto, D. E. M. (2007). Universidade Estadual De Campinas.

Mikhaeil, M., Gaderer, M., \& Dawoud, B. (2020). On the Development of an Innovative Adsorber Plate Heat $\begin{array}{lll}\text { Exchanger for. Energy, } & 118272 .\end{array}$ https://doi.org/10.1016/j.energy.2020.118272

Miyazaki, T., \& Akisawa, A. (2009). The influence of heat exchanger parameters on the optimum cycle time of adsorption chillers. Applied Thermal Engineering, 29(13), $2708-2717$.

https://doi.org/10.1016/j.applthermaleng.2009.01.005

Mohammadzadeh Kowsari, M., Niazmand, H., \& Tokarev, M. M. (2018). Bed configuration effects on the finned flat-tube adsorption heat exchanger performance: Numerical modeling and experimental validation. Applied Energy, $213,540-554$. https://doi.org/10.1016/j.apenergy.2017.11.019

Mohammed, R. H., Mesalhy, O., Elsayed, M. L., \& Chow, L. C. (2017). Novel compact bed design for adsorption cooling systems: parametric numerical study. International Journal of Refrigeration. https://doi.org/10.1016/j.ijrefrig.2017.04.028

Naderipour, A., Abdul-malek, Z., Arshad, R. N., Kamyab, H., Chelliapan, S., Ashokkumar, V., \& Tavalaei, J. (2021). Assessment of carbon footprint from transportation, electricity, water, and waste generation: towards utilisation of renewable energy sources. Clean Technologies and Environmental Policy, 23(1), 183-201. https://doi.org/10.1007/s10098-020-02017-4

Naeimi, A., Nowee, S. M., Ali, H., \& Amiri, A. (2020). Chemical Engineering Research and Design Numerical simulation and theoretical investigation of a multi-cycle dualevaporator adsorption desalination and cooling system. Chemical Engineering Research and Design, 156, 402-413. https://doi.org/10.1016/j.cherd.2020.02.016

Ng, K. C., Thu, K., Chakraborty, A., Saha, B. B., \& Chun, W. G. (2009). Solar-assisted dual-effect adsorption cycle for the production of cooling effect and potable water. International Journal of Low-Carbon Technologies, 4(2), 61-67. https://doi.org/10.1093/ijlct/ctp008

Qu, T. F., Wang, R. Z., \& Wang, W. (2001). Study on heat and mass recovery in adsorption refrigeration cycles. 21, 439452.

Raj, R., \& Baiju, V. (2019). Thermodynamic analysis of a solar powered adsorption cooling and desalination system. Energy Procedia, $\quad 158, \quad 885-891$. https://doi.org/10.1016/j.egypro.2019.01.226

Rezk, H., Alsaman, A. S., Al-Dhaifallah, M., Askalany, A. A., Abdelkareem, M. A., \& Nassef, A. M. (2019). Identifying optimal operating conditions of solar-driven silica gel based adsorption desalination cooling system via modern optimization. Solar Energy, 181, 475-489. https://doi.org/10.1016/j.solener.2019.02.024

Sakoda, A., \& Suzuki, M. (1984). Fundamental study on solar powered adsorption cooling system. Journal of Chemical Engineering of Japan, 17(1), 52-57. https://doi.org/10.1252/jcej.17.52

Sumathy, K., \& Zhongfu, L. I. (1999). Experiments With SolarPowered Adsorption Ice-Maker. 16, 704-707.

Thu, K., Chakraborty, A., Saha, B. B., \& Ng, K. C. (2013). Thermophysical properties of silica gel for adsorption desalination cycle. Applied Thermal Engineering, 50(2), 1596-1602. https://doi.org/10.1016/j.applthermaleng.2011.09.038

Thu, K., Chakraborty, A., Kim, Y., Myat, A., Baran, B., \& Choon, K. (2013). Numerical simulation and performance investigation of an advanced adsorption desalination cycle. DES, $\quad 308, \quad 209-218$. https://doi.org/10.1016/j.desal.2012.04.021

Ullah, K. R., Saidur, R., Ping, H. W., Akikur, R. K., \& Shuvo, N. H. (2013). A review of solar thermal refrigeration and cooling methods. Renewable and Sustainable Energy Reviews, 24 , 499-513. https://doi.org/10.1016/j.rser.2013.03.024

Wang, W., \& Wang, R. (2005). Investigation of non-equilibrium adsorption character in solid adsorption refrigeration cycle. 680-684. https://doi.org/10.1007/s00231-004-0582-9

Woo, S. Y., Lee, H. S., Ji, H., Moon, D. S., \& Kim, Y. D. (2019). Silica gel-based adsorption cooling cum desalination system: Focus on brine salinity, operating pressure, and its effect on performance. Desalination, 467, 136-146. https://doi.org/10.1016/j.desal.2019.06.016

Youssef, P. G., Mahmoud, S. M., \& Al-dadah, R. K. (2015). 
Citation: AlRubaiee, J.F., Latteiff, F.A., Mahdi, J.M., Atiya, M.A., and Majdi, H.S. (2021) Desalination of agricultural wastewater by solar adsorption system: a numerical study. Int. Journal of Renewable Energy Development, 10(4), 901-910, doi: 10.14710/ijred.2021.38798

910 |

Performance analysis of four bed adsorption water desalination / refrigeration system , comparison of AQSOAZ02 to silica - gel. DES, 375, 100-107. https://doi.org/10.1016/j.desal.2015.08.002

Zejli, D., Benchrifa, R., Bennouna, A., \& Bouhelal, O. K. (2004). A solar adsorption desalination device: First simulation

$$
\text { results. Desalination, 168(1-3), 127-135. }
$$$$
\text { https://doi.org/10.1016/j.desal.2004.06.178 }
$$

Zhang, H., Ma, H., Liu, S., Wang, H., Sun, Y., \& Qi, D. (2020). Investigation on the operating characteristics of a pilotscale adsorption desalination system. Desalination, 473, 114196. https://doi.org/10.1016/j.desal.2019.114196 